\author{
Marquette University \\ e-Publications@Marquette
}

$5-2005$

\title{
Effects of Load Magnitude on Diagnosing Broken Bar Faults in Induction Motors Using the Pendulous Oscillation of the Rotor Magnetic Field Orientation
}

\author{
Behrooz Mirafzal \\ Marquette University \\ Nabeel Demerdash \\ Marquette University, nabeel.demerdash@marquette.edu
}

Follow this and additional works at: https://epublications.marquette.edu/electric_fac

Part of the Computer Engineering Commons, and the Electrical and Computer Engineering Commons

\section{Recommended Citation}

Mirafzal, Behrooz and Demerdash, Nabeel, "Effects of Load Magnitude on Diagnosing Broken Bar Faults in Induction Motors Using the Pendulous Oscillation of the Rotor Magnetic Field Orientation" (2005).

Electrical and Computer Engineering Faculty Research and Publications. 194.

https://epublications.marquette.edu/electric_fac/194 
Marquette University

e-Publications@Marquette

\title{
Department of Electrical and Computer Engineering Faculty Research and Publications/College of Engineering
}

This paper is NOT THE PUBLISHED VERSION.

Access the published version at the link in the citation below.

IEEE Transactions on Industry Applications, Vol. 41, No. 3 (May-June 2005): 771-783. DOI. This article is (C) Institute of Electrical and Electronic Engineers (IEEE) and permission has been granted for this version to appear in e-Publications@Marquette. Institute of Electrical and Electronic Engineers (IEEE) does not grant permission for this article to be further copied/distributed or hosted elsewhere without the express permission from Institute of Electrical and Electronic Engineers (IEEE).

\section{Effects Of Load Magnitude on Diagnosing Broken Bar Faults in Induction Motors Using the Pendulous Oscillation of The Rotor Magnetic Field Orientation}

\author{
B. Mirafzal
}

Department of Electrical and Computer Engineering, Marquette University, Milwaukee, WI N.A.O. Demerdash

Department of Electrical and Computer Engineering, Marquette University, Milwaukee, WI

\section{Abstract:}

The effects of load level on the ability to diagnose broken bar faults in squirrel-cage induction motors are studied in this paper. The pendulous oscillation of the rotor magnetic field orientation is implemented as a fault signature for rotor fault diagnostic purposes at steady-state operations. 
Moreover, the effects of load level on the low-side band component of the stator current spectrum, and associated diagnostic difficulties in this approach particularly in the presence of motor operation from pulsewidth-modulation drives, are reported as well. These investigations were performed through testing 2-hp and 5-hp induction motors over a wide range of load levels and control drives. The results of these tests and investigations demonstrate the efficacy of the pendulous oscillation signature as a diagnostic means that can be used for a wide range of motor operating conditions.

\section{Major Nomenclature}

\begin{tabular}{|c|l|}
\hline$\delta(t)$ & Pendulous oscillation of the rotor (or resultant) magnetic field. \\
\hline$\delta_{1}(t)$ & Fundamental component of the pendulous oscillation. \\
\hline$\Delta \delta$ & Swing angle or the range of the pendulous oscillation. \\
\hline$\Delta \delta_{1}$ & Swing angle or the range of the fundamental component of the pendulous oscillation. \\
\hline$\tilde{\tilde{\delta}}$ & Analytically estimated swing angle. \\
\hline$N_{b}$ & Number of rotor bars per pair of poles. \\
\hline$n_{b}$ & Number of adjacent broken bars in a squirrel cage. \\
\hline
\end{tabular}

\section{SECTION II. Introduction}

THE basic principles underlying the concept of pendulous oscillation of rotor magnetic field orientation due to broken bars has been introduced in a previous investigation [1]. This phenomenon can be observed using merely the voltages and currents at the motor terminals without any need for obtaining the motor speed. In this paper, this technique is further refined in a manner that enables an investigator to detect the presence of one broken bar fault or even a manufacturing defect in a healthy rotor cage. Meanwhile, the effects of load level were studied experimentally here for 2-hp and 5-hp induction motors. In the case of the 5-hp motor, the effects of load level were studied when the motor was run under three different excitations: sinusoidal direct-line, pulsewidth-modulation (PWM) openloop constant volts-per-hertz control, and PWM closed-loop field-oriented control drive. These experimental results, as will be seen later, lead these authors to conclude that the method presented here constitutes indeed a simple and reliable technique for broken bar fault detection. This technique, side-by-side with the well-known sideband component techniques [2]-[3][4][5][6][7], will lead to an improvement in the reliability of the online rotor cage condition monitoring of induction motors.

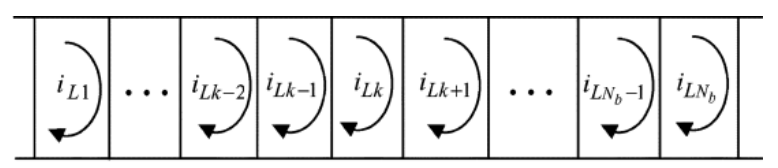

(a)

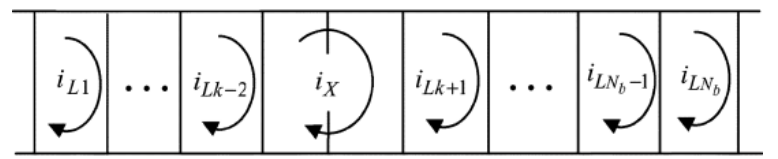

(b)

Fig. 1. Rotor cage developed circuit representation of (a) healthy cage and (b) broken bar cage.

Meanwhile, to provide a better physical understanding of this phenomenon, an analytically estimated swing angle is formulated here based on electromagnetic principles in electric machines for a 
generalized case in which the rotor cage has $N_{b}$ bars per pair of poles and $n_{b}$ adjacent broken bars. It will be shown in this formulation that the analytically estimated swing angle is a function of both $N_{b}$ and $n_{b}$ for a limited number of broken bars. However, the swing angle is impacted by the space harmonics caused by the machine's design factors such as core saturation, stator and rotor tooth-slot geometry effects, and the discrete nature of the nonsinusoidal stator winding distributions in actual electric machines. Accordingly, in order to take into account these effects, a so-called harmonics effect factor $k_{h}$ is introduced in the formulation. This formulation may allow manufactures to provide a set of diagnostic characteristic curves of the swing angle versus the number of broken bars for each class of their product lines.

The next section elucidates the physics of the pendulous oscillation phenomenon in the rotor magnetic field orientation due to the presence of rotor broken bars. The next section also presents the abovementioned formulation in which the relationship between the swing angle $\Delta \delta$ and the parameters $N_{b}$ and $n_{b}$ is being discussed. It has to be emphasized that this formulation is given here only to provide a better physical understanding of this phenomenon, as well as a possible diagnostic characteristic curve. However, for practical motor diagnostics purposes, the swing angle $\Delta \delta$ was obtained through space-vector concepts applied to the easily accessible motor terminal measurements, namely stator voltages and currents. Accordingly, an online broken bar diagnostic approach is presented in Section IV, in which the input signals are two of the motor terminal voltages and their corresponding motor terminal currents.

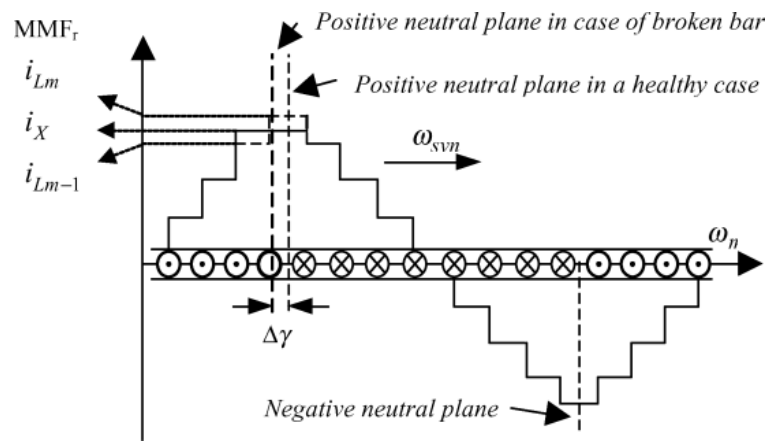

Fig. 2. Broken bar disturbs the peak of the rotor MMF profile.

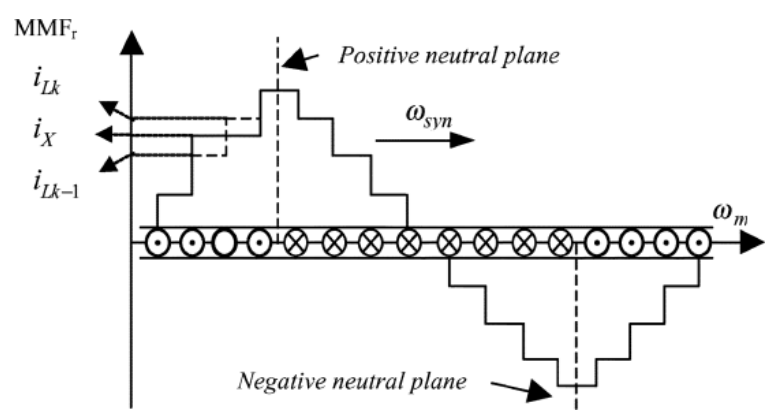

Fig. 3. Broken bar does not disturb the peak of the rotor MMF profile. 


\section{SECTION III. Pendulous Oscillation Phenomenon in Rotor Magnetic Field Orientation}

The pendulous oscillation phenomenon in rotor magnetic field orientation is an electromagnetic phenomenon which can not be entirely investigated from circuitry point of view in an induction machine. In other words, the shape of the rotor magnetomotive force (MMF) waveform and corresponding space harmonics of the rotor cage have to be considered for this investigation. This phenomenon is studied in this section using the rotor MMF waveform, first in the presence of one broken bar, then in the presence of $n_{b}$ adjacent broken bars.

\section{A. Rotor MMF Distortion Due to One Broken Bar}

The concept of the existence of a pendulous oscillation phenomenon associated with the presence of broken bars in a squirrel cage induction motor was first introduced in [1]. Here, the objective of this section is to establish a generalized formulation for the "pendulous oscillation" of the rotor magnetic field for any cage with $N_{b}$ bars per pair of poles with one broken-bar fault, using the rotor MMF waveform. Consider the rotor loop currents $i_{L 1}, i_{L 2}, \ldots, i_{L N_{b}}$ in a squirrel cage, depicted here in Fig. 1, including the healthy cage and the case of a cage with one broken bar. The rotor MMF waveform is depicted here in terms of these loop currents using Ampere's law, and the fact that the rotor bar currents are expressed in terms of the loop currents as follows:

$$
i_{b k}(t)=i_{L k-1}(t)-i_{L k}(t), \quad k=1,2, \ldots, N_{b} .
$$

Accordingly, in Figs. 2 and 3, the rotor MMF waveforms are depicted in the case of one broken bar fault for two different time instances in a slip cycle. Thus, it has to be mentioned that Figs.

2 and 3 depict two different positions of the broken bar with respect to a synchronously rotating frame of reference, since the MMF speed, $\omega_{\text {syn }}$, is greater than the rotor speed (or rotational speed of the broken bar position), $\omega_{m}$, in an induction motor. In this study, the critical locations of positions of a broken bar are where they are passing the peaks of the MMF profile. Hence, the remainder of this discussion will be focused on two different locations for the broken bar position with respect to the rotor MMF waveform shown in Figs. 2 and 3. In case (1), Fig. 2, the broken bar disturbs the magnitude of the peak of the rotor MMF shown here by the solid lines, and in case (2), Fig. 3, the broken bar does not disturb the magnitude of the peak of the rotor MMF. In Figs. 2 and 3, the positive and negative magnetic neutral planes indicate the locations of the magnetic north pole and south pole, respectively. In general, a neutral plane (or magnetic axis) is located where inherently the magnetic flux lines are equally divided between two sides of that plane. In other words, it will be shown later that in case (2), Fig. 3, in spite of the bar breakage in the positive portion of the rotor MMF, the neutral plane is not relocated from its original location in a healthy case. However, in case (1), Fig. 2, the positive neutral plane tends to the left side of its original location in a healthy case by the angular shift $\Delta \gamma$. Although this relocation occurs periodically in a continuous manner over half a slip cycle, or with an angular frequency of $2\left(\omega_{\text {syn }}-\omega_{m}\right)$, the maximum relocation theoretically occurs twice while the broken bar is passing the positive and negative peak spans of the rotor MMF waveform. 
In order to quantify the broken bar distortion effect on the rotor MMF waveform, the magnitude of the current $i_{X}$ in the newly formed loop resulting from the bar breakage (see Fig. 1) has to be calculated. This can be done by applying the well-known magnetic field concept that $\nabla \cdot \vec{B}=0$ for the healthy cage shown in Fig. $1(\mathrm{a})$. That is, the surface integral of flux density, $B=\left(\mu_{o} \mathrm{MMF}_{r}\right) / g$, over any closed surface is equal to zero. This enables one to write the following equation for the cage shown in Fig. 1(a), assuming that there is no significant axial flux component:

$$
\begin{gathered}
\frac{\mu_{o} A_{\text {loop }}}{g}\left(i_{L 1}+\cdots+i_{L k-2}+i_{L k-1}+i_{L k}\right. \\
\left.+i_{L k+1}+\cdots+i_{L N_{b}}\right)=0
\end{gathered}
$$

where $i_{L k}$ indicates the loop current in the $k$ th loop, $A_{\text {loop }}$ is the rotor loop area, and $g$ is the effective (equivalent) air-gap height. Meanwhile, applying the fundamental magnetic field concept, $\nabla \cdot \vec{B}=0$, for the cage with one broken bar, shown in Fig. 1(b), in which the area of the loop containing the broken bar equals twice the area of a healthy loop, yields the following:

$$
\begin{gathered}
\frac{\mu_{o} A_{\text {loop }}}{g}\left(i_{L 1}+\cdots+i_{L k-2}+2 i_{X}\right. \\
\left.+i_{L k+1}+\cdots+i_{L N_{b}}\right)=0 .
\end{gathered}
$$

Here, it is assumed as an approximation, the respective healthy loop currents in Fig. 1(a) and (b) are equal, for a limited number of broken bars. In other words, the healthy loop currents in Fig. 1(b) will not significantly be distorted due to the broken bar fault; see, in Appendix A, the results of a timestepping finite-element (TSFE) model for justification of that approximating assumption. Accordingly, a quick comparison between (2) and (3) yields the following approximation for the distorted loop current, $i_{X}$ :

$$
i_{X}=\frac{1}{2}\left(i_{L k-1}+i_{L k}\right)
$$

Now, the next step is to calculate the angular shift $\Delta \gamma$ in the rotor MMF waveforms in the aforementioned cases, shown in Fig. 2 [case (1)], and Fig. 3 [case (2)]. Here, it has to be pointed out that the positive neutral plane of the rotor MMF waveform, or magnetic axis, is located where the magnetic flux lines are equally divided between two sides of the neutral plane. It means that the area of the positive portion of the rotor MMF waveform is split into two equal areas by the neutral plane (line), provided that the equivalent air-gap height is constant everywhere around the cylindrical surface of the rotor. It has to be emphasized that the effective air-gap height will not be a constant 
throughout the circumference of the rotor, due to effects of core saturation and the stator slotting which vary throughout a pole pitch.

According to the above-mentioned definition for the neutral plane (magnetic axis), and through the use of (4), one can see that in case (2) the neutral plane's location will not change, that is, $\Delta \gamma=0$. However, the angular shift, $\Delta \gamma$, is not zero in case (1), see Fig. 4, and it can be expressed as follows:

$$
\Delta \gamma=\gamma-\frac{\pi}{N_{b}}=\left(\frac{\pi}{N_{b}}\right)\left(\frac{i_{L m}-i_{X}}{i_{X}}\right) .
$$

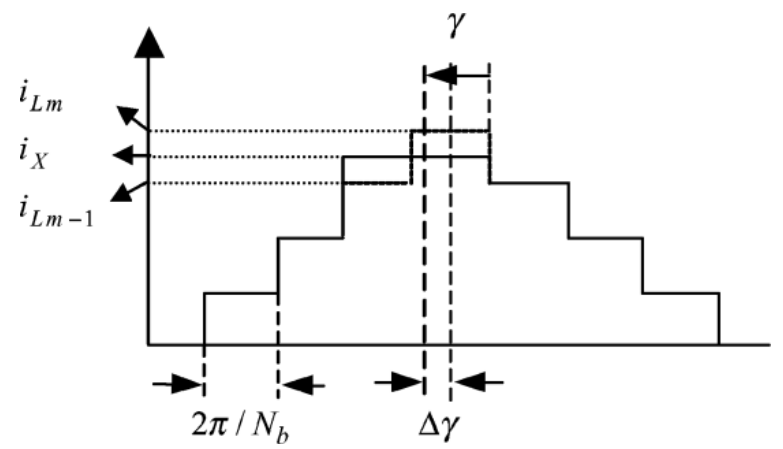

Fig. 4. Broken bar disturbs the peak of the rotor MMF profile.

Substituting for the current $i_{X}$ from (4) into (5), where $k=m$ in case (1), yields the total magnitude of the estimated swing angle of the magnetic axis, $\Delta \tilde{\delta}$, which can be written according to the fact that $\Delta \tilde{\delta}=(2 \Delta \gamma) / 2$ in radians as follows [1]:

$$
\Delta \tilde{\delta}=\frac{2 \Delta \gamma}{2}=\Delta \gamma=\left(\frac{\pi}{N_{b}}\right)\left(\frac{i_{L m}-i_{L m-1}}{i_{L m}+i_{L m-1}}\right) .
$$

\section{B. Rotor MMF Distortion Due to $n_{b}$ Broken Bars}

A similar procedure, as discussed in the previous section, can be applied here for a rotor cage with $n_{b}$ adjacent broken bars. This results in the following general formulation for the analytically estimated swing angle, $\Delta \tilde{\delta}$, in radians:

$$
\tilde{\Delta}=\left(\frac{\pi}{N_{b}}\right)\left(\frac{n_{b} i_{L m}-\sum_{k=m-1}^{m-n_{b}} i_{L k}}{i_{L m}+\sum_{k=m-1}^{m-n_{b}} i_{L k}}\right) .
$$


For details of the steps leading to the expression in (7) see Appendix B. Upon taking into account of the fundamental components of the rotor loop currents as well as the harmonic factor $k_{h}$, we have the following:

$$
\begin{gathered}
\Delta \tilde{\delta}=k_{h}\left(\frac{\pi}{N_{b}}\right) \\
\times\left(\frac{\left(2 n_{b}+1\right) \sin \left(\pi / N_{b}\right)-\sin \left[\left(2 n_{b}+1\right)\left(\pi / N_{b}\right)\right.}{\sin \left(\frac{\pi}{N_{b}}\right)+\sin \left[\left(2 n_{b}+1\right)\left(\frac{\pi}{N_{b}}\right)\right]}\right)
\end{gathered}
$$

(8)

where the $k_{h}$ could be obtained by manufacturers either during the design stage using TSFE methods or testing of an existing machine. It should be pointed out that because of the assumption implied in the derivation of the current $i_{X}$ in (4) and (B.1) in Appendix B involving the neglect of loop current distortion effects in the conductively undisturbed loops, it is in these authors' judgment that the generalized formulation of (8) is valid for a limited number of adjacent bar breakages where $1 \leq n_{b}<$ $\left(N_{b} / 4\right)$ (see Fig. 4).
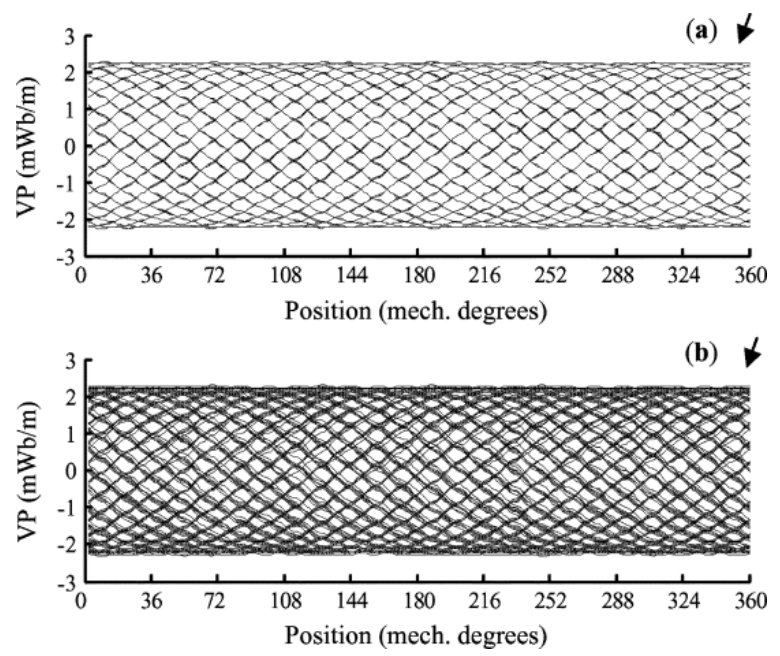

Fig. 5. Vector potential waveforms obtained from FE calculation, 2-hp healthy motor. (a) Healthy rotor cage. (b) Rotor cage with three broken bars.

This observation will be revisited in the analysis of the experimental test results given in Section VI. For details of the derivations leading to (8) and the justification of the accompanying approximating assumption see Appendix B. Here, based on (8) one can theoretically deduce as shown in Appendixes $A$ and $B$ that induction machines will fail under full-load condition if the number of adjacent broken bars $n_{b}$ reaches half the number of rotor bars per pair of poles, that is. when $n_{b}=N_{b} / 2$. In these authors' judgment, this is heuristically expected from the physical nature of the operation of induction motors. 


\section{SECTION IV. Pendulous Oscillation Phenomenon-FE Electromagnetic Field}

\section{Evidence}

The objective of this section is to present an electromagnetic field based evidence of the existence of the motor magnetic field pendulous oscillation due to broken bar faults using TSFE modeling and computation. An analytical proof of the existence of the pendulous oscillation due to broken bars was presented in the previous section using the rotor MMF waveform. However, the analytical proof of this phenomenon was established based on two simplifying assumptions: namely, that the height of the equivalent air gap is uniform, and that the healthy rotor current loops do not suffer significant current magnitude distortions during bar breakage. Here, in this section, a 2-hp motor was simulated using the Flux2D- MAGSOFT TSFE software, naturally, excluding the above-mentioned simplifying assumptions.

Here, the mid-air-gap magnetic vector potential (MVP) plots over a slip cycle obtained under a healthy and a three-broken-bar fault conditions, are shown in Fig. 5(a) and (b), respectively. In order to demonstrate the pendulous oscillation phenomenon, 200 instances separated by the same time interval over a slip cycle were selected and their corresponding vector potential waveforms were plotted in Fig. 5(a) and (b), respectively. In other words, any sine-shaped curve in this family of MVP plots indicates the MVP distribution at a time instant versus the position which is $360^{\circ}$ covering the entire mid-air-gap circumference. As one can observe, in the healthy case of Fig. 5(a), these MVP waveforms occur on top of each other throughout the duration of the slip cycle, while this is not the case for the three-broken-bars fault in which these waveforms do not occur on top of each other due to the existence of a three-broken-bars fault, thus leading to the banded (blurring) appearance of the MVP sine waveforms of Fig. $5($ b).

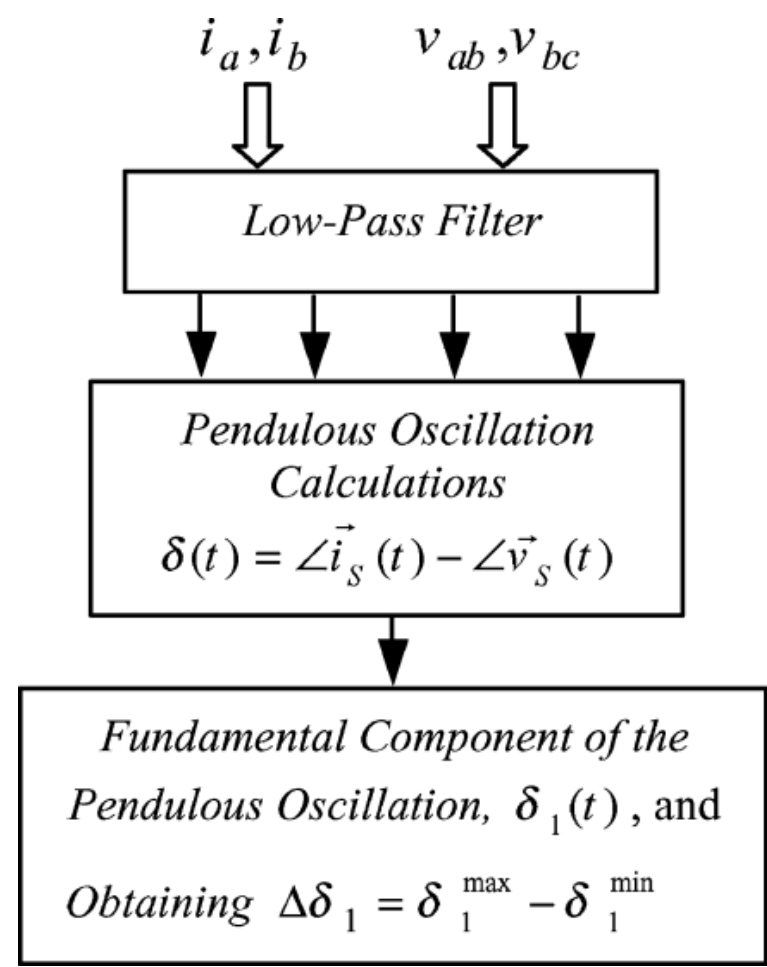

Fig. 6. Functional block diagram of calculating swing angle, $\Delta \delta_{1}$. 
This "blurring" means that as time progresses the MVP travels with a slight speed perturbation in the case of broken bars. This waveform speed perturbation around its synchronous speed generates the so-called pendulous oscillation. Hence, it can be concluded that the mid-air-gap magnetic field has two motions: 1) a main motion at synchronous speed and 2) a pendulous oscillation.

\section{SECTION V. A Space-Vector Method for Detecting the Rotor Magnetic Field Pendulous Oscillation}

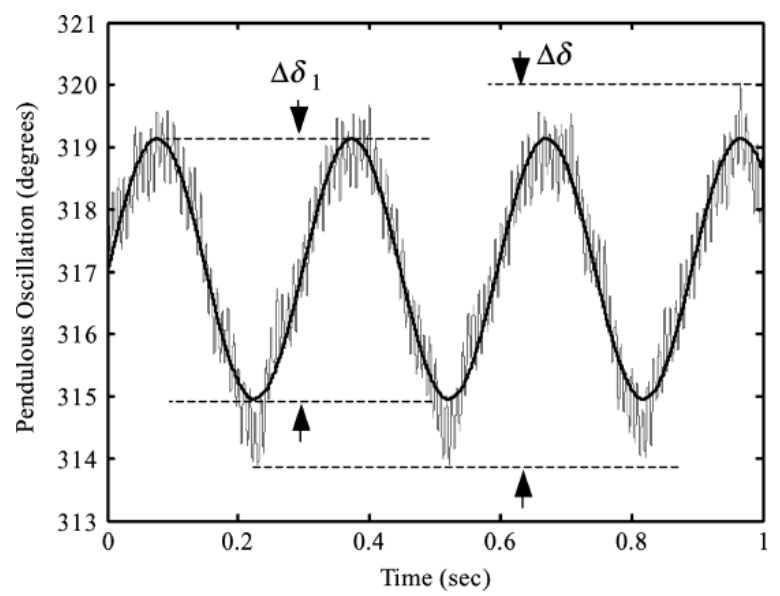

Fig. 7. Pendulous oscillation and its fundamental component in degrees versus time in seconds for the 5-hp induction motor in the case of three broken bars, full-load condition.

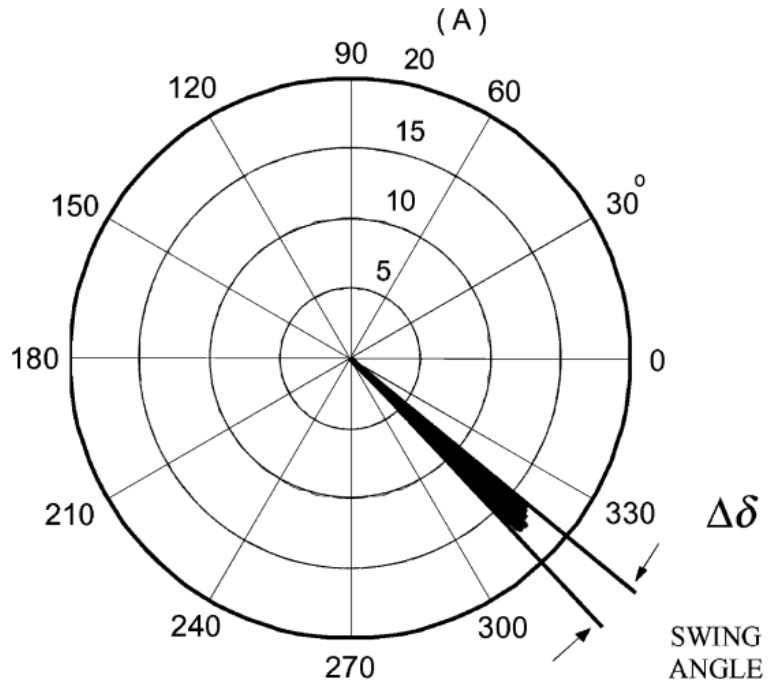

Fig. 8. Swing angle $\Delta \delta$ in degrees versus the $\operatorname{Re}(i \vec{s}(\mathrm{t}))$ in amperes in a polar coordinate in the case of three broken bars, full-load condition.

If there were access to the rotor loop currents, the swing angle due to $n_{b}$ adjacent broken bars could be calculated using the space vector of the loop currents. Of course, in a squirrel-cage induction motor with the present technology this is not a practical prospect. However, this angle can be indirectly obtained using measurable stator quantities. This can be accomplished by detecting the rotor or resultant magnetic field orientation through space-vector formulations [8]. A method based on detecting the rotor magnetic field orientation was presented by these authors in [1]. However, stator 
resistance and inductances were necessary parameters in that process of the measurement (detection) of the rotor magnetic field. In this paper, these authors demonstrate the finding that the resultant magnetic field orientation can be considered as the diagnostic signature in order to observe the effects of rotor field orientation in the presence of a broken bar fault. The functional block diagram of this technique is shown in Fig. 6 in which the space vectors of the stator currents $\vec{i}_{s}$ and voltages $\vec{v}_{s}$ are defined as follows:

$$
\begin{aligned}
\vec{i}_{s}(t) & =\frac{2}{3}\left(\left(i_{a}-i_{b}\right)+\alpha\left(i_{b}-i_{c}\right)+\alpha^{2}\left(i_{c}-i_{a}\right)\right) \\
& =\left(i_{a}-i_{b}\right)+j \sqrt{3}\left(i_{a}+i_{b}\right) \\
\vec{v}_{s}(t) & =\frac{2}{3}\left(v_{a b}+\alpha v_{b c}+\alpha^{2} v_{c a}\right) \\
& =\left(v_{a b}\right)+j\left(v_{a b}+2 v_{b c}\right) / \sqrt{3}
\end{aligned}
$$

(9) (10)

where the currents and voltages $i_{a}, i_{b}, v_{a b}$, and $v_{b c}$, are the input signals of the online fault diagnostic system depicted in Fig. 6. In Fig. 7, the pendulous oscillation $\delta(t)=\angle \vec{i}_{S}-\angle \vec{v}_{S}$ which is obtained as the difference between the current space-vector angle $\angle \vec{i}_{s}(t)$ and the voltage space-vector angle $\angle \vec{v}_{s}(t)$, as a function of time as well as its fundamental component $\delta_{1}(t)$, are shown for a cage with three broken bars at full-load condition. Meanwhile, the corresponding polar plot of the swing angle $\Delta \delta$, obtained from laboratory testing of the 5-hp motor, is shown in Fig. 8. Here, in this technique, the swing angle $\Delta \delta_{1}$ (see Figs. 6 and 7) is considered as the diagnostic index. This index leads one to easily detect (distinguish) a cage with one broken bar from a healthy cage, despite the fact that the total swing angle measure $\Delta \delta$ might be contaminated with noise, especially for a low number of broken bars.

In this procedure, first the input signals are sampled using an A/D converter, and subsequently are filtered using a low-pass filter. Then, the output signals of the low-pass filter are collected (or saved) over a period greater than a slip cycle. In order to obtain the fundamental component of the pendulous oscillation $\delta_{1}(t)$ with a high resolution, an integer number of the swing angle cycles is required. Notice that the frequency of the pendulous oscillation is equal to twice the slip frequency and a speed sensor is unnecessary in this technique. This process of determination of the fundamental component was accordingly accomplished through a data processing algorithm in conjunction with the least-squares technique [9], [10]. 


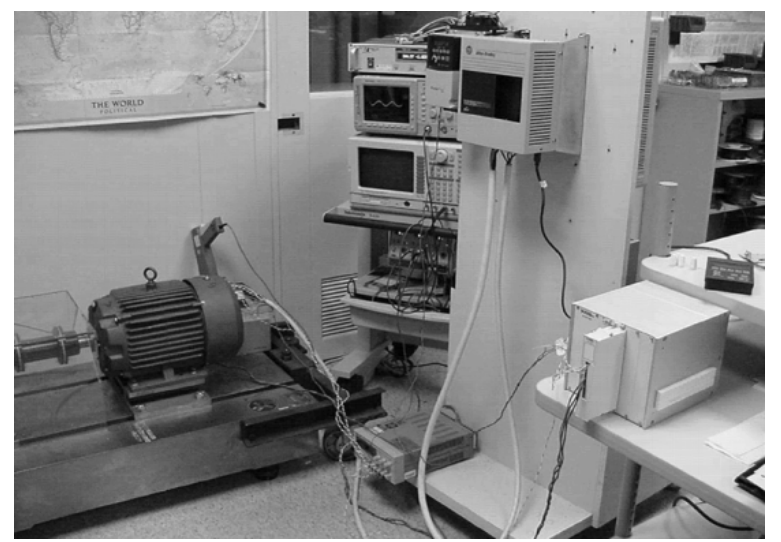

Fig. 9. Laboratory test setup for the 5-hp induction motor.

\section{SECTION VI. Experimental Results}

A 2-hp two-pole $230-\mathrm{V}$ induction motor with 36 rotor bars was tested in the laboratory under a healthy rotor condition as well as one-, three-, and five broken-bar fault conditions. These tests were performed under a sinusoidal direct-line excitation. Also, a 5-hp six-pole 460-V induction motor with 45 rotor bars was tested in the laboratory under a healthy rotor condition, as well as one through fourbroken-bar faults. These tests were performed when the 5-hp motor was energized from three different power supplies: 1) sinusoidal direct-line excitation; 2) PWM open-loop constant volts-perhertz control; and 3) PWM closed-loop field-oriented control. The last two tests with control drives were performed using the commercially available AB Power Flex40 and AB 1336 Impact drives, respectively. The carrier frequency of both of these PWM drives was set to be $4 \mathrm{kHz}$. In these tests, the data acquisition laboratory test equipment was a National Instrument LabView SCXI-1000 device, while the sampling rate was set to be $50 \mathrm{~K}$ samples per second. Fig. 9 shows the laboratory test setup for testing the 5-hp induction motor under healthy and faulty conditions.

In order to study the effects of load level on the two methods of rotor broken bar fault diagnostics: 1) using the fundamental component of pendulous oscillation which was introduced above and 2) using the well-known low sideband (LSB) component of the stator phase current spectrum [2]-[3][4][5] [6], the following test scenarios were selected and implemented for measurement in the laboratory:

TABLE I Comparison Between the Swing Angle in Degrees and LSB Magnitude in Decibels, Sinusoidal Excitation Full-Load 2-hp Induction Motor

\begin{tabular}{|l|l|l|l|}
\hline & $\begin{array}{l}\text { Low Side Band Magnitude in } \\
\text { (db) }\end{array}$ & & $\begin{array}{l}\text { Swing Angle in } \\
\text { (degrees) }\end{array}$ \\
\hline $\begin{array}{l}\text { Rotor Cage } \\
\text { Condition }\end{array}$ & Rectangular Windowing & $\begin{array}{l}\text { Hanning } \\
\text { Windowing }\end{array}$ & \multicolumn{1}{c|}{$\Delta \boldsymbol{\delta}_{\mathbf{1}}$} \\
\hline Healthy & -49.0 & -56.5 & 0.3302 \\
\hline One Broken Bar & -45.3 & -43.4 & 1.2180 \\
\hline Three Broken Bars & -31.8 & -31.2 & 5.6429 \\
\hline Five Broken Bars & -24.6 & -25.9 & 9.8292 \\
\hline
\end{tabular}


TABLE II Comparison Between the Swing Angle in Degrees and LSB Magnitude in Decibels, Sinusoidal Excitation $85 \%$ of Full Load 2-hp Induction Motor

\begin{tabular}{|l|l|l|l|}
\hline & $\begin{array}{l}\text { Low Side Band Magnitude in } \\
(\mathbf{d b})\end{array}$ & & $\begin{array}{l}\text { Swing Angle in } \\
\text { (degrees) }\end{array}$ \\
\hline $\begin{array}{l}\text { Rotor Cage } \\
\text { Condition }\end{array}$ & Rectangular Windowing & $\begin{array}{l}\text { Hanning } \\
\text { Windowing }\end{array}$ & \multicolumn{1}{c|}{$\Delta \boldsymbol{\delta}_{\mathbf{1}}$} \\
\hline Healthy & -44.0 & -51.9 & 0.3401 \\
\hline One Broken Bar & -46.0 & -43.8 & 1.1795 \\
\hline Three Broken Bars & -29.1 & -31.6 & 5.5437 \\
\hline Five Broken Bars & -25.8 & -25.8 & 9.6982 \\
\hline
\end{tabular}

TABLE III Comparison Between the Swing Angle in Degrees and LSB Magnitude in Decibels, Sinusoidal Excitation $50 \%$ of Full Load 2-hp Induction Motor

\begin{tabular}{|l|l|l|l|}
\hline & $\begin{array}{l}\text { Low Side Band Magnitude in } \\
\text { (db) }\end{array}$ & Swing Angle in \\
\hline $\begin{array}{l}\text { Rotor Cage } \\
\text { Condition }\end{array}$ & Rectangular Windowing & $\begin{array}{l}\text { Hanning } \\
\text { Windowing }\end{array}$ & \multicolumn{1}{|c|}{$\Delta \boldsymbol{\delta}_{1}$} \\
\hline Healthy & -55.7 & -53.9 & 0.3761 \\
\hline One Broken Bar & -42.1 & -44.1 & 1.1929 \\
\hline Three Broken Bars & -33.4 & -32.6 & 5.4163 \\
\hline Five Broken Bars & -27.9 & -26.5 & 9.3811 \\
\hline
\end{tabular}

TABLE IV Comparison Between the Swing Angle in Degrees and LSB Magnitude in Decibels, Sinusoidal Excitation Full-Load 5-hp Induction Motor

\begin{tabular}{|l|l|l|l|}
\hline & $\begin{array}{l}\text { Low Side Band Magnitude in } \\
\text { (db) }\end{array}$ & Swing Angle in \\
\hline $\begin{array}{l}\text { Rotor Cage } \\
\text { Condition }\end{array}$ & Rectangular Windowing & $\begin{array}{l}\text { Hanning } \\
\text { Windowing }\end{array}$ & \multicolumn{1}{|c|}{$\Delta \boldsymbol{\delta}_{\mathbf{1}}$} \\
\hline Healthy & -43.3 & -74.6 & 0.0473 \\
\hline One Broken Bar & -45.6 & -47.0 & 1.1570 \\
\hline Two Broken Bars & -40.8 & -40.0 & 2.6214 \\
\hline Three Broken Bars & -35.9 & -35.1 & 4.1769 \\
\hline Four Broken Bars & -33.8 & -33.1 & 5.3092 \\
\hline
\end{tabular}

TABLE V Comparison Between the Swing Angle in Degrees and LSB Magnitude in Decibels, Sinusoidal Excitation $75 \%$ of Full Load 5-hp Induction Motor

\begin{tabular}{|l|l|l|l|}
\hline & $\begin{array}{l}\text { Low Side Band Magnitude in } \\
(\mathbf{d b})\end{array}$ & & $\begin{array}{l}\text { Swing Angle in } \\
\text { (degrees) }\end{array}$ \\
\hline $\begin{array}{l}\text { Rotor Cage } \\
\text { Condition }\end{array}$ & Rectangular Windowing & $\begin{array}{l}\text { Hanning } \\
\text { Windowing }\end{array}$ & \multicolumn{1}{c|}{$\Delta \boldsymbol{\delta}_{\mathbf{1}}$} \\
\hline Healthy & -48.3 & -76.5 & 0.0416 \\
\hline One Broken Bar & -43.2 & -46.6 & 0.9761 \\
\hline Two Broken Bars & -37.0 & -39.5 & 2.2204 \\
\hline
\end{tabular}




\begin{tabular}{|l|l|l|l|}
\hline Three Broken Bars & -38.3 & -36.0 & 3.4513 \\
\hline Four Broken Bars & -32.0 & -33.0 & 4.2493 \\
\hline
\end{tabular}

TABLE VI Comparison Between the Swing Angle in Degrees and LSB Magnitude in Decibels, Sinusoidal Excitation $50 \%$ of Full Load 5 -hp Induction Motor

\begin{tabular}{|l|l|l|l|}
\hline & $\begin{array}{l}\text { Low Side Band Magnitude in } \\
\text { (db) }\end{array}$ & & $\begin{array}{l}\text { Swing Angle in } \\
\text { (degrees) }\end{array}$ \\
\hline $\begin{array}{l}\text { Rotor Cage } \\
\text { Condition }\end{array}$ & Rectangular Windowing & $\begin{array}{l}\text { Hanning } \\
\text { Windowing }\end{array}$ & \multicolumn{1}{|c|}{$\Delta \boldsymbol{\delta}_{\mathbf{1}}$} \\
\hline Healthy & -60.5 & -66.0 & 0.0427 \\
\hline One Broken Bar & -45.1 & -47.2 & 0.7074 \\
\hline Two Broken Bars & -38.5 & -40.0 & 1.5582 \\
\hline Three Broken Bars & -35.3 & -36.8 & 2.3709 \\
\hline Four Broken Bars & -34.9 & -34.4 & 2.8733 \\
\hline
\end{tabular}

TABLE VII Comparison Between the Swing Angle in Degrees and LSB Magnitude in Decibels, PWM Open-Loop Drive Full-Load 5-hp Induction Motor

\begin{tabular}{|l|l|l|l|}
\hline & $\begin{array}{l}\text { Low Side Band Magnitude in } \\
(\mathbf{d b})\end{array}$ & & $\begin{array}{l}\text { Swing Angle in } \\
\text { (degrees) }\end{array}$ \\
\hline $\begin{array}{l}\text { Rotor Cage } \\
\text { Condition }\end{array}$ & Rectangular Windowing & $\begin{array}{l}\text { Hanning } \\
\text { Windowing }\end{array}$ & \multicolumn{1}{|c|}{$\Delta \boldsymbol{\delta}_{\mathbf{1}}$} \\
\hline Healthy & -50.0 & -64.0 & 0.0866 \\
\hline One Broken Bar & -43.2 & -46.6 & 1.2457 \\
\hline Two Broken Bars & -41.6 & -39.8 & 2.7226 \\
\hline Three Broken Bars & -35.8 & -35.0 & 4.3178 \\
\hline Four Broken Bars & -34.6 & -33.0 & 5.6961 \\
\hline
\end{tabular}

TABLE VIII Comparison Between the Swing Angle in Degrees and LSB Magnitude in Decibels, PWM Open-Loop Drive $75 \%$ of Full Load 5-hp Induction Motor

\begin{tabular}{|l|l|l|l|}
\hline & $\begin{array}{l}\text { Low Side Band Magnitude in } \\
\text { (db) }\end{array}$ & & $\begin{array}{l}\text { Swing Angle in } \\
\text { (degrees) }\end{array}$ \\
\hline $\begin{array}{l}\text { Rotor Cage } \\
\text { Condition }\end{array}$ & Rectangular Windowing & $\begin{array}{l}\text { Hanning } \\
\text { Windowing }\end{array}$ & \multicolumn{1}{|c|}{$\Delta \boldsymbol{\delta}_{\mathbf{1}}$} \\
\hline Healthy & -51.0 & -60.6 & 0.1157 \\
\hline One Broken Bar & -42.0 & -46.0 & 0.9535 \\
\hline Two Broken Bars & -38.6 & -39.5 & 2.2214 \\
\hline Three Broken Bars & -37.0 & -36.2 & 3.6217 \\
\hline Four Broken Bars & -34.3 & -33.0 & 4.5219 \\
\hline
\end{tabular}

TABLE IX Comparison Between the Swing Angle in Degrees and LSB Magnitude in Decibels, PWM OpenLoop Drive $50 \%$ of Full Load 5-hp Induction Motor 


\begin{tabular}{|l|l|l|l|}
\hline & $\begin{array}{l}\text { Low Side Band Magnitude in } \\
\text { (db) }\end{array}$ & & $\begin{array}{l}\text { Swing Angle in } \\
\text { (degrees) }\end{array}$ \\
\hline $\begin{array}{l}\text { Rotor Cage } \\
\text { Condition }\end{array}$ & Rectangular Windowing & $\begin{array}{l}\text { Hanning } \\
\text { Windowing }\end{array}$ & \multicolumn{1}{|c|}{$\Delta \boldsymbol{\delta}_{\mathbf{1}}$} \\
\hline Healthy & -43.0 & -65.0 & 0.0877 \\
\hline One Broken Bar & -43.3 & -55.5 & 0.8062 \\
\hline Two Broken Bars & -39.6 & -40.5 & 1.6100 \\
\hline Three Broken Bars & -36.4 & -37.2 & 2.4389 \\
\hline Four Broken Bars & -36.8 & -34.5 & 3.1334 \\
\hline
\end{tabular}

TABLE X Comparison Between the Swing Angle in Degrees and LSB Magnitude in Decibels, PWM Closed -Loop Drive Full-Load 5-hp Induction Motor

\begin{tabular}{|l|l|l|l|}
\hline & $\begin{array}{l}\text { Low Side Band Magnitude in } \\
(\mathbf{d b})\end{array}$ & & $\begin{array}{l}\text { Swing Angle in } \\
\text { (degrees) }\end{array}$ \\
\hline $\begin{array}{l}\text { Rotor Cage } \\
\text { Condition }\end{array}$ & Rectangular Windowing & $\begin{array}{l}\text { Hanning } \\
\text { Windowing }\end{array}$ & \multicolumn{1}{c|}{$\Delta \boldsymbol{\delta}_{\mathbf{1}}$} \\
\hline Healthy & -24.5 & -38.3 & 0.2024 \\
\hline One Broken Bar & -35.0 & -34.9 & 0.4201 \\
\hline Two Broken Bars & -30.8 & -29.8 & 0.4585 \\
\hline Three Broken Bars & -23.4 & -23.2 & 0.4620 \\
\hline Four Broken Bars & -21.8 & -22.2 & 1.1027 \\
\hline
\end{tabular}

TABLE XI Comparison Between the Swing Angle in Degrees and LSB Magnitude in Decibels, PWM Closed-Loop Drive 75\% of Full Load 5-hp Induction Motor

\begin{tabular}{|l|l|l|l|}
\hline & $\begin{array}{l}\text { Low Side Band Magnitude in } \\
(\mathbf{d b})\end{array}$ & & $\begin{array}{l}\text { Swing Angle in } \\
\text { (degrees) }\end{array}$ \\
\hline $\begin{array}{l}\text { Rotor Cage } \\
\text { Condition }\end{array}$ & Rectangular Windowing & $\begin{array}{l}\text { Hanning } \\
\text { Windowing }\end{array}$ & \multicolumn{1}{c|}{$\Delta \boldsymbol{\delta}_{\mathbf{1}}$} \\
\hline Healthy & -38.5 & -39.3 & 0.1415 \\
\hline One Broken Bar & -37.7 & -37.7 & 0.2588 \\
\hline Two Broken Bars & -29.8 & -29.8 & 0.6349 \\
\hline Three Broken Bars & -22.0 & -22.0 & 1.1349 \\
\hline Four Broken Bars & -21.8 & -21.8 & 1.3720 \\
\hline
\end{tabular}

- 2-hp sinusoidal direct-line excitation at

1. full-load condition under healthy cage and one, three, and five broken bar faults (see Table I);

2. $85 \%$ of full-load condition under healthy cage and one, three, and five broken bar faults (see Table II);

3. $50 \%$ of full-load condition under healthy cage and one, three, and five broken bar faults (see Table III);

- 5-hp sinusoidal direct-line excitation at 
1. full-load condition under healthy cage and one through four broken bar faults (see Table IV);

2. $75 \%$ of full-load condition under healthy cage and one through four broken bar faults (see Table V);

3. $50 \%$ of full load condition under healthy cage and one through four broken bar faults (see Table VI);

- 5-hp PWM (4 kHz carrier frequency) open-loop constant volts-per-frequency drive

1. full-load condition under healthy cage and one through four broken bar faults (see Table VII);

2. $75 \%$ of full-load condition under healthy cage and one through four broken bar faults (see Table VIII);

3. $50 \%$ of full-load condition under healthy cage and one through four broken bar faults (see Table IX);

- 5-hp PWM (4 kHz carrier frequency) closed-loop field-oriented control drive;

1. full-load condition under healthy cage and one through four broken bar faults (see Table $\mathrm{X})$;

2. $75 \%$ of full-load condition under healthy cage and one through four broken bar faults (see Table XI)

3. $50 \%$ of full-load condition under healthy cage and one through four broken bar faults (see Table XII).

TABLE XII Comparison Between the Swing Angle in Degrees and LSB Magnitude in Decibels, PWM Closed -Loop- 50\% of Full Load 5-hp Induction Motor

\begin{tabular}{|c|c|c|c|}
\hline & $\begin{array}{l}\text { Low Side Band Magnitude in } \\
\text { (db) }\end{array}$ & & $\begin{array}{l}\text { Swing Angle in } \\
\text { (degrees) }\end{array}$ \\
\hline $\begin{array}{l}\text { Rotor Cage } \\
\text { Condition }\end{array}$ & Rectangular Windowing & $\begin{array}{l}\text { Hanning } \\
\text { Windowing }\end{array}$ & $\Delta \delta_{1}$ \\
\hline Healthy & -38.8 & -38.2 & 0.2673 \\
\hline One Broken Bar & -37.4 & -37.1 & 0.4483 \\
\hline Two Broken Bars & -32.6 & -31.0 & 0.9863 \\
\hline Three Broken Bars & -27.0 & -25.0 & 1.4615 \\
\hline Four Broken Bars & -24.4 & -22.3 & 2.3603 \\
\hline
\end{tabular}




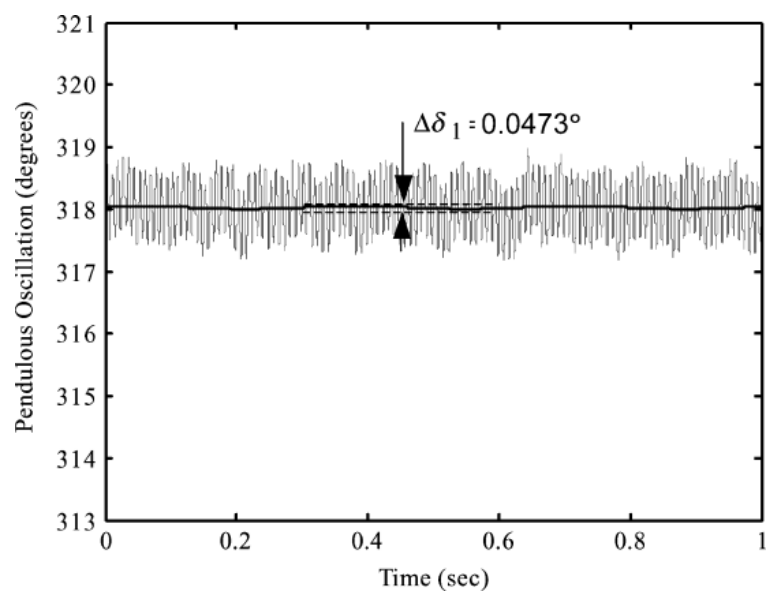

Fig. 10. Pendulous oscillation and its fundamental component in degrees versus time in seconds for the 5-hp induction motor in a healthy situation, full-load condition.

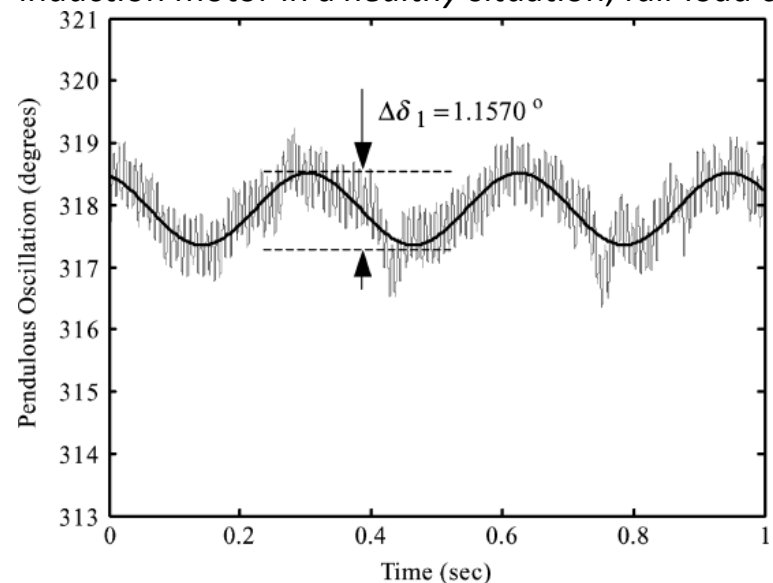

Fig. 11. Pendulous oscillation and its fundamental component in degrees versus time in seconds for the 5-hp induction motor in the case of one broken bar, full-load condition.

\section{SECTION VII. Analysis of Experimental Test Results}

For a direct-line sinusoidal excitation of the 5-hp induction motor, Table IV and Figs. $10-12$ show the pendulous oscillation $\delta(t)$, its fundamental component $\delta_{1}(t)$, and the swing angle $\Delta \delta_{1}$ in degrees for a healthy, one, and two adjacent broken-bar faults under full-load conditions. As one can observe, a rotor with one broken-bar fault can be easily distinguished from a healthy cage. Moreover, the correlation between the swing angle $\Delta \delta_{1}$ and the number of broken bars leads to the conclusion that, not only can a faulty case be distinguished from a healthy case, but also the degree of the fault severity can be acquired using this swing angle fault index. In this technique, a nonzero value of the swing angle $\Delta \delta_{1}$ means that there is a defect in the rotor bars. Hence, a healthy cage should not generate a nonzero value of swing angle. However, there exists no such ideal condition 


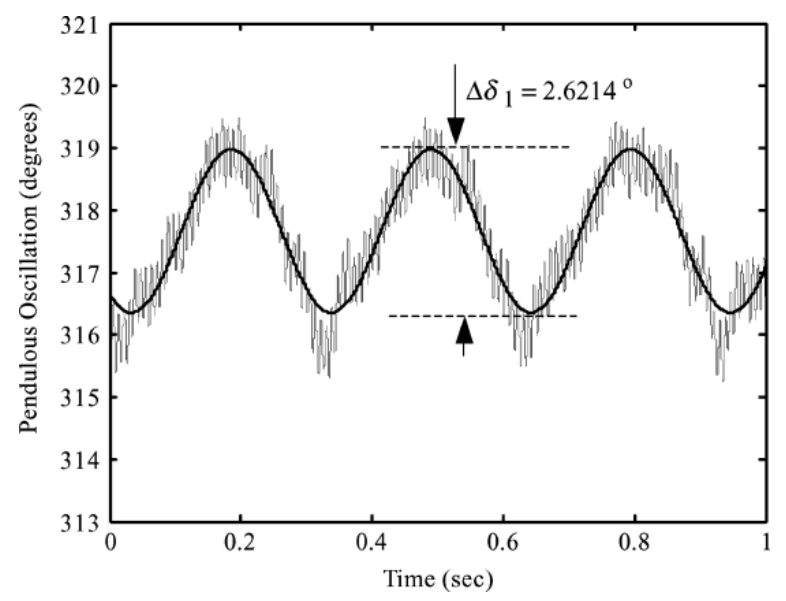

Fig. 12. Pendulous oscillation and its fundamental component in degrees versus time in seconds for the 5-hp induction motor in the case of two broken bars, full-load condition.

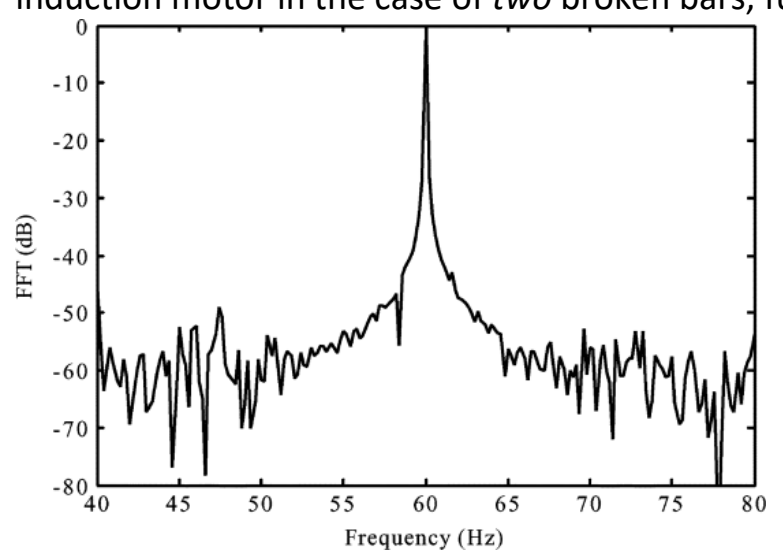

Fig. 13. FFT spectrum of the stator phase current for the 5-hp induction motor in the case of one broken bar, $50 \%$ of full load, PWM open-loop drive.

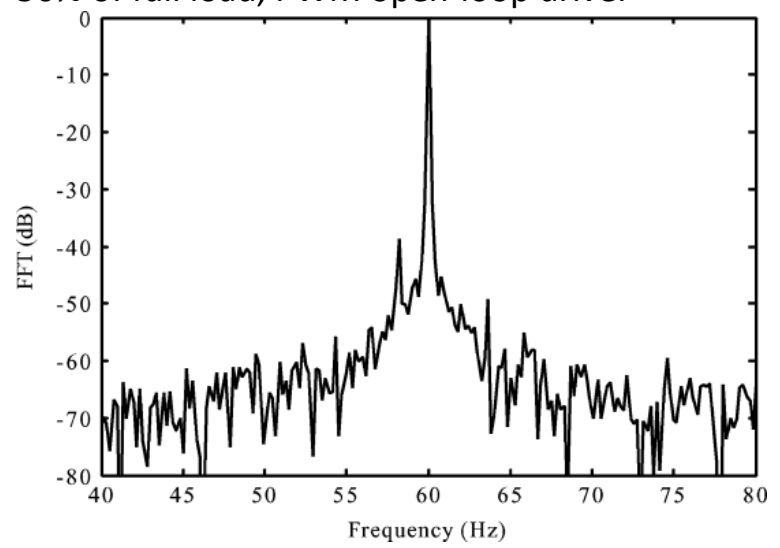

Fig. 14. FFT spectrum of the stator phase current for the 5 -hp induction motor in a healthy case, $50 \%$ of full-load, PWM closed-loop drive. 


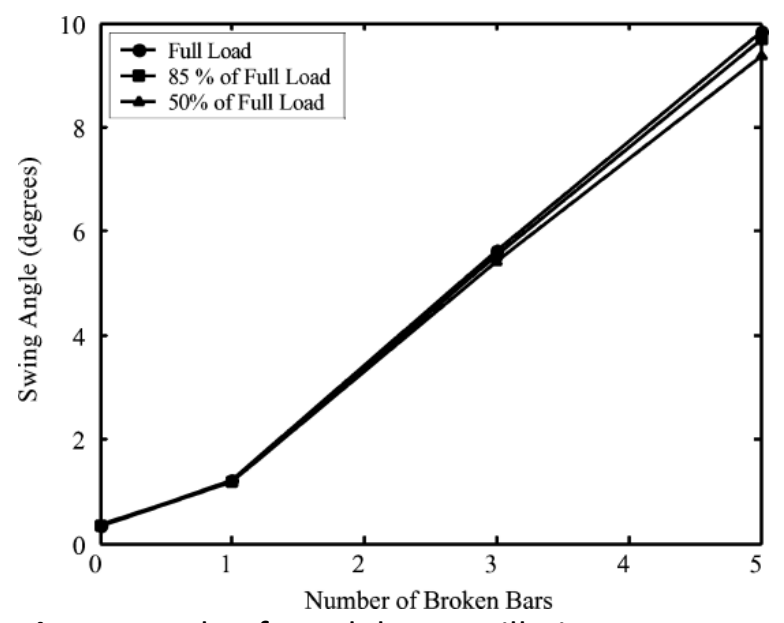

Fig. 15. Angle of pendulous oscillation versus number of broken bars, sinusoidal excitation, 2-hp induction motor.

due to the presence of even slight manufacturing imperfections under normal industrial tolerances. Hence, a nonzero value of swing angle is obtained even under healthy motor conditions, e.g., see Fig. 10 , where $\Delta \delta_{1}=0.0473^{\circ}$. Accordingly, the swing angle under healthy conditions can be measured and saved as the threshold value. Meanwhile, it should be pointed out again that the frequency of the pendulous oscillation due to broken-bar faults is equal to twice the slip frequency. Therefore, this frequency characteristic of the swing angle enables an online condition monitoring system to distinguish a broken-bar fault from other phenomena which may produce other magnetic field oscillations with different frequencies.

In case of the test results given in Table IX for a PWM open-loop control of the 5-hp motor, Fig. 13 shows the fast Fourier transform (FFT) spectrum of the corresponding stator phase current in the presence of one broken bar, at $50 \%$ of full load. Here, it is difficult to observe any LSB component in the stator phase current spectrum shown in Fig. 13. Moreover, for the same motor, Fig. 14 shows the FFT spectrum of the stator phase current in a healthy case for $50 \%$ of full load under PWM closed-loop control, which corresponds to the test results of Table XII. It can be easily observed that there are two LSB components close to the fundamental component, which is not what one would expect for a healthy condition and, consequently, such a signal could lead to considerable ambiguities in rotor broken-bar fault diagnostics. Therefore, without detracting from the diagnostic value of classical spectral analysis techniques, it can be concluded that the LSB index may not be as reliable an approach for partial load levels in cases of PWM excitations. 


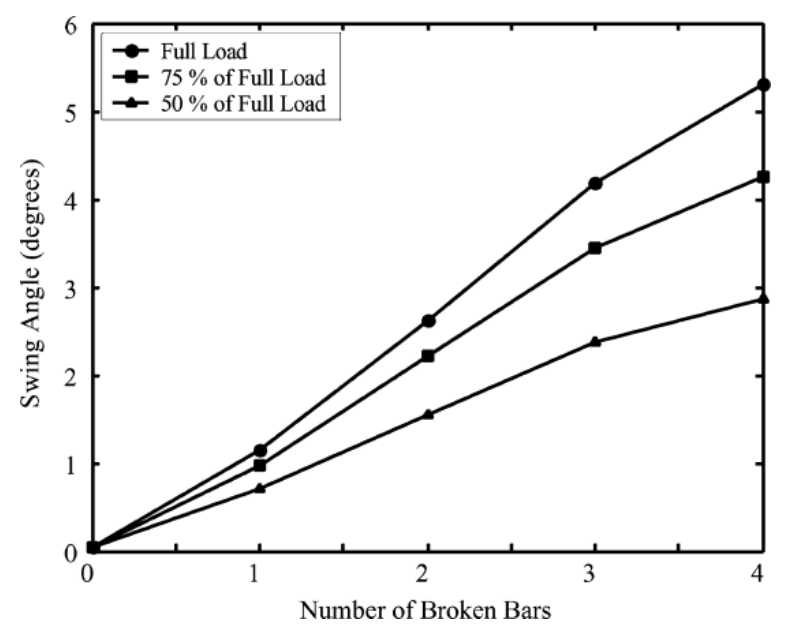

Fig. 16. Angle of pendulous oscillation versus number of broken bars, sinusoidal excitation, 5-hp induction motor.

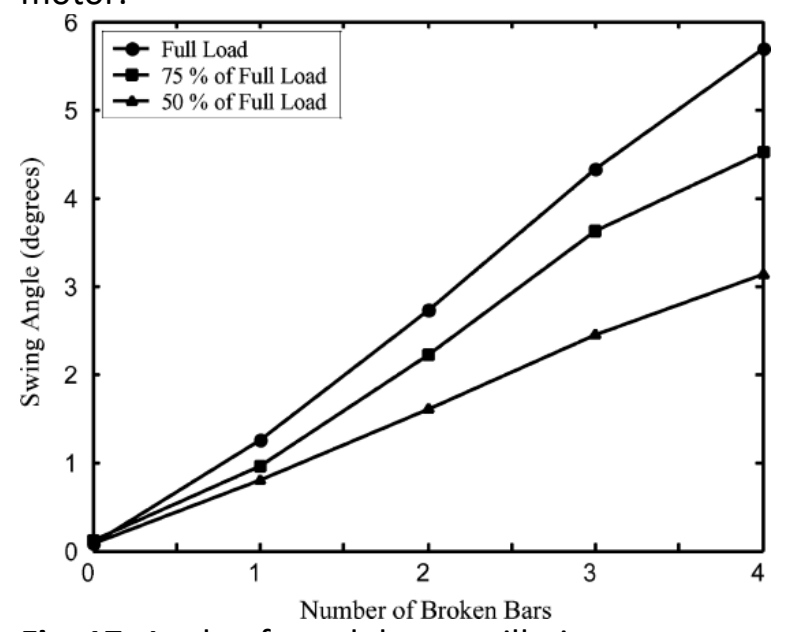

Fig. 17. Angle of pendulous oscillation versus number of broken bars, PWM open-loop control drive, 5-hp induction motor.

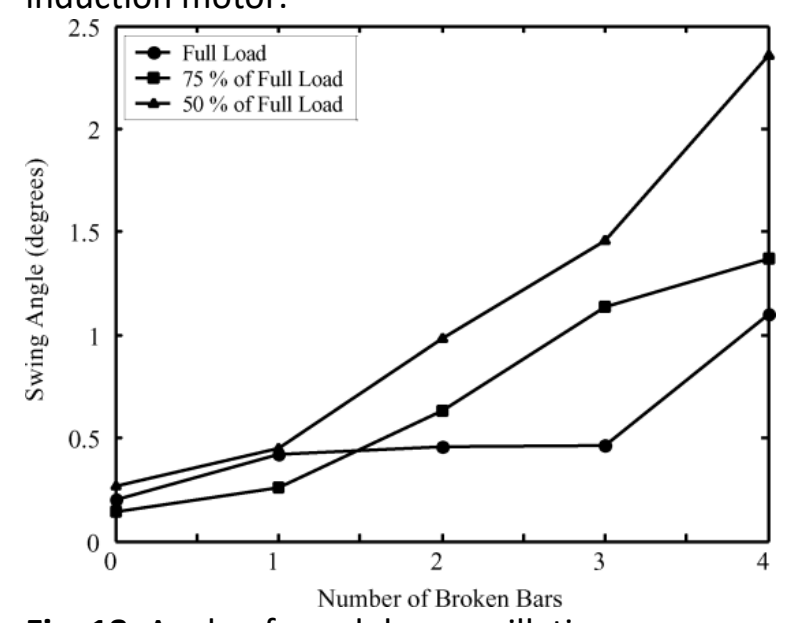

Fig. 18. Angle of pendulous oscillation versus number of broken bars, PWM closed-loop control drive, 5-hp induction motor. 


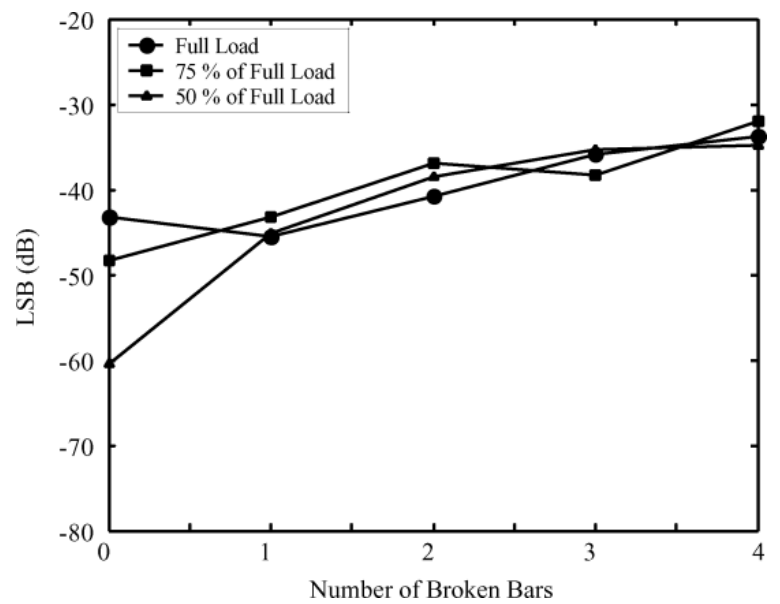

Fig. 19. LSB component in the terminal current spectrum versus number of broken bars, sinusoidal excitation, 5hp induction motor.

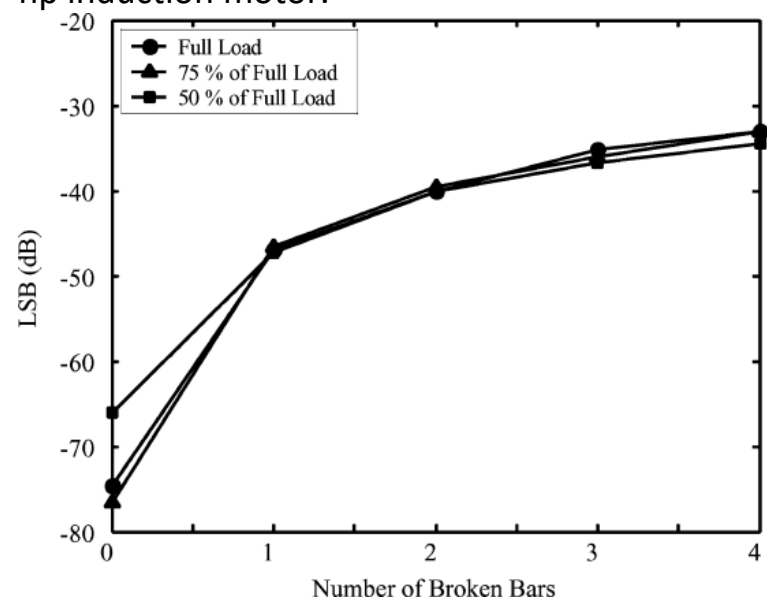

Fig. 20. LSB component in the terminal current spectrum (using Hanning Windowing) versus number of broken bars, sinusoidal excitation, 5-hp induction motor.

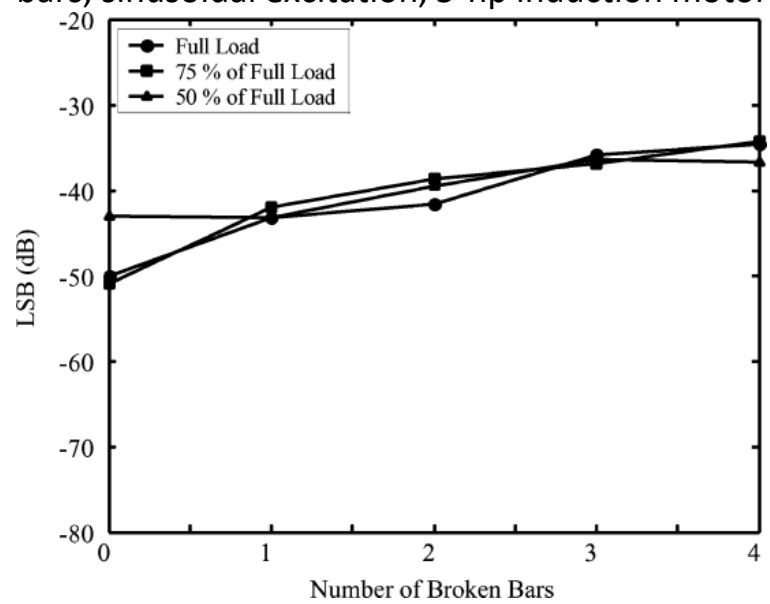

Fig. 21. LSB component in the terminal current spectrum versus number of broken bars, PWM-open loop control drive, 5-hp induction motor. 


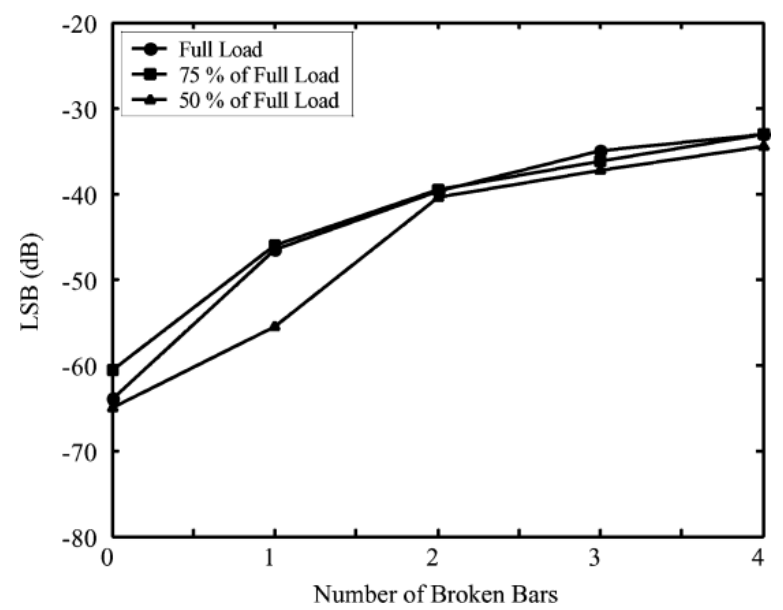

Fig. 22. LSB component in the terminal current spectrum (with Hanning windowing) versus number of broken bars, PWM open-loop control drive, 5-hp induction motor.

The plots showing the swing angle diagnostic index $\Delta \delta_{1}$ and the spectral LSB indexes as functions of the number of broken bars for the various tests given in Tables I-XII are illustrated in Figs. 15 -24. Elaboration on the analysis of these results is given next.

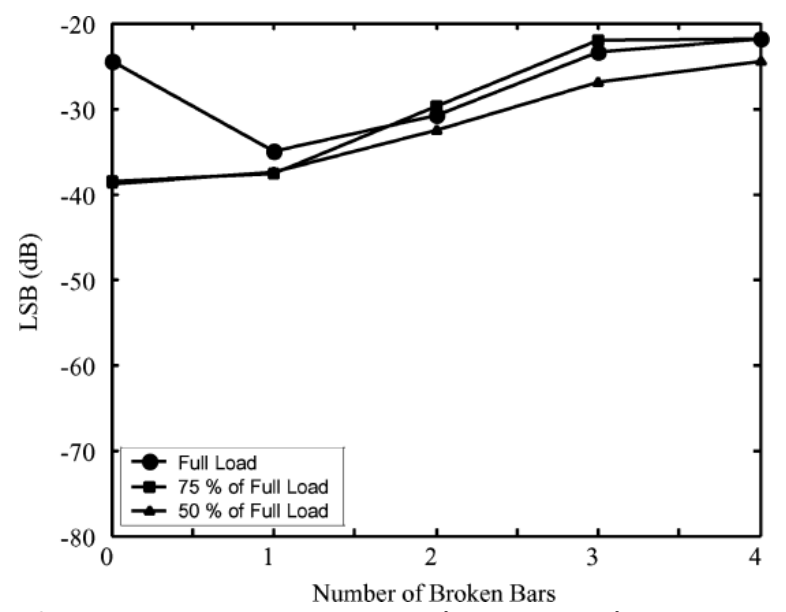

Fig. 23. LSB component in the terminal current spectrum versus number of broken bars, PWM closed-loop control drive, 5-hp induction motor.

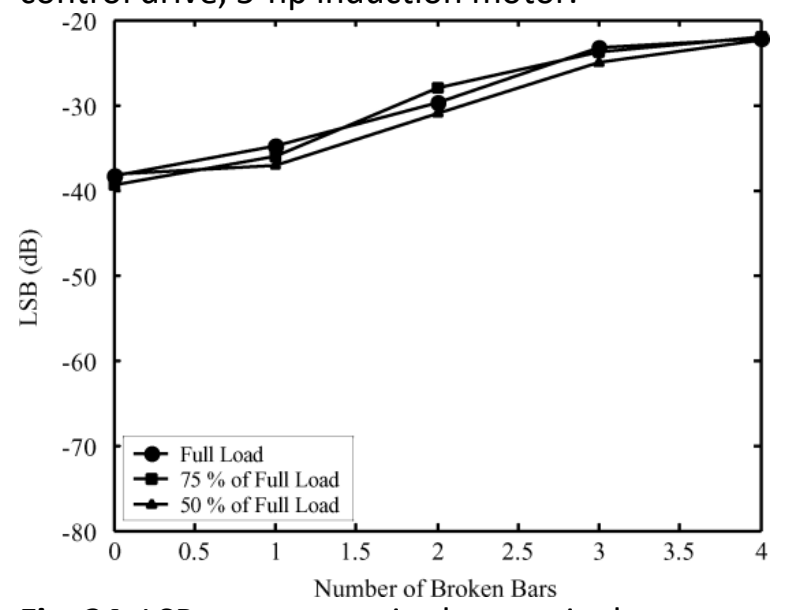

Fig. 24. LSB component in the terminal current spectrum (with Hanning windowing) versus number of broken bars, PWM closed-loop control drive, 5-hp induction motor. 
A main disadvantage of the spectral analysis of the stator current is the impact of the phenomenon referred to as side-lobe leakage, which sometimes can mask the sideband components, due to inherent (rectangular) windowing of finite data sets [10], [11]. One can observe the masking effect of this phenomenon in the results given in Fig. 13, as well as Figs. 19, and 21. However, window weighting (e.g., using Hanning windowing [10]) mitigates the effects of finite data sets at the expense of decreasing the spectral resolution [10], [11], see Figs. 20, and 22. Moreover, spectral sampling, as imposed by the discrete Fourier transformation (DFT), can sometimes produce misleading results [10]. In other words, if the data sampling frequency is not proportional to the frequency of the fundamental component, the effect of the side-lobe leakage will be sometimes significant enough to mask the sideband components even using the windowing techniques. That is, the sampling frequency of the data acquisition system should be adjusted based on the fundamental frequency which may not be feasible in many practical applications. This may lead to difficulty, especially if an induction motor is driven by an adjustable-speed drive.

The swing angle diagnostic index $\Delta \delta_{1}$ in Figs. 15-17 shows that there is always a difference between the resulting angle $\Delta \delta_{1}$ for a healthy cage and that angle of a cage with even one broken bar. Moreover, the severity of broken-bar faults can be evaluated using the swing angle index. These two characteristics of the swing angle make it somewhat superior to the LSB index. As one can observe from Figs. 20 and 22, an increase in LSB magnitude tends to exhibit a quasi-saturation profile. Meanwhile, as one can see from Figs. 16 and 17, the swing angle decreases with a decrease in the load level in the case of the 5-hp motor, which makes heuristic sense because less load means less rotor circuit's impact observable from the stator side. However, in the case of the 2-hp motor the swing angle does not vary with the load level (see Fig. 15). This may be attributable to the fact that the number of rotor bars per pole in the case of the 2 -hp motor is $(36 / 2)=18$, while this number is only $(45 / 6)=7.5$ in the case of the 5-hp motor.

The same trend for the swing angle versus number of broken bars observed in Figs. $15-17$ holds true for the closed-loop PWM drive case of Fig. 18, except for the full-load condition under which a diminution in the swing angle increase with an increase in the number of broken bars took place at full load. This is due to the controller's compensation actions inherent in field-oriented PWM closed-loop control drives that are tuned to full-load operation.

SECTION VIII. Conclusion 

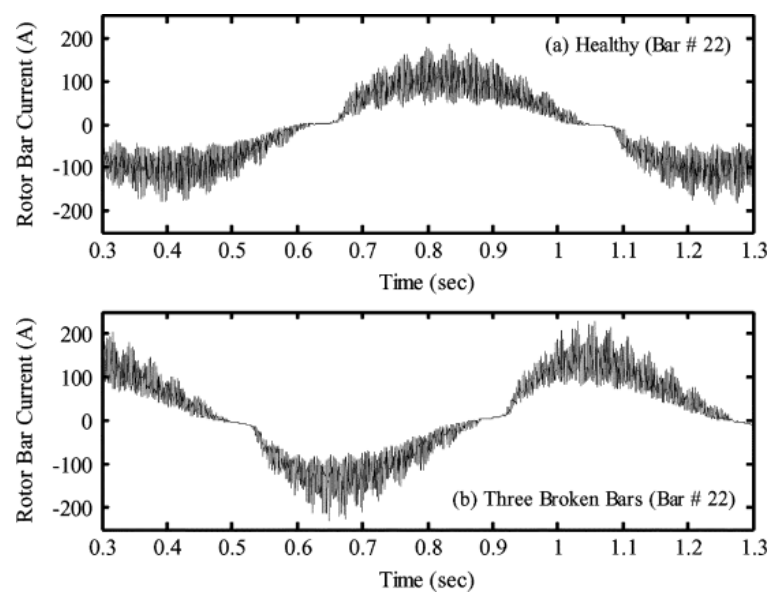

Fig. 25. FE simulation results of the rotor bar currents of "Bar \# 22" in (a) a healthy cage and (b) a cage with three broken bars fault.
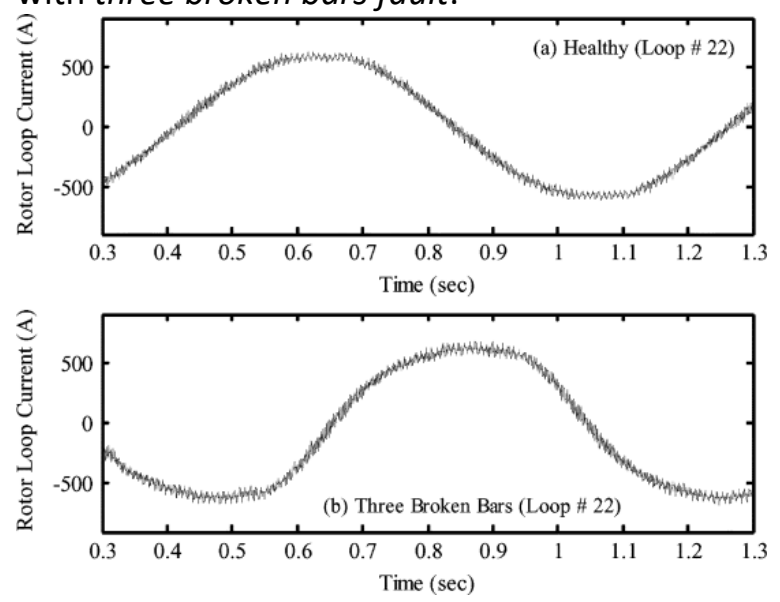

Fig. 26. FE simulation results of the rotor loop currents of "Loop \# 22" in (a) a healthy cage and (b) a cage with three broken bars fault.

In this paper, a simple and reliable broken rotor bar fault diagnostics method using the motor's resultant magnetic field, which is based on the pendulous oscillation of the rotor magnetic field orientation phenomenon, has been introduced and investigated for load levels from $50 \%$ to $100 \%$ of full load for a set of 2- and 5-hp induction motors. These tests were performed in the case of the 5-hp motor under sinusoidal direct-line excitation as well as a PWM open-loop constant volts-per-hertz control drive and a PWM closed-loop field oriented control drive. The results confirmed that under a variety of load levels, even the subtle fault of one broken bar can be distinguished (detected) from a healthy rotor cage. The input signals of this method are merely two motor terminal voltages and two motor terminal currents, without any need for motor speed measurements. The method was shown to be robust and unambiguous in identifying the extent of the number of broken bars. Hence, a correlation between the swing angle and other fault indices leads to an improvement in the reliability of the online rotor cage condition monitoring of induction motors. 


\section{ACKNOWLEDGMENT}

The authors wish to thank Dr. P. Schmidt and Dr. F. Discenzo of Rockwell Corporation for providing the 5-hp test motors and providing access to their laboratory facilities. The authors also wish to thank R. Bartos, S. Dellinger, and Dr. D. Ionel of A. O. Smith Corporation for providing the 2-hp test motor and providing access to their laboratory facilities.

\section{Appendix}

The objective of this appendix is to give evidence to the validity of the approximating assumption that the healthy loop currents in a defective rotor cage are not significantly different from the healthy loop currents in a healthy rotor cage. It should be pointed out that this assumption as an approximation will be valid only for a case with relatively low number of broken bars with respect to the number of bars per pair of poles. Meanwhile, the outcome of this assumption was to demonstrate that the magnetic axis due to broken bar faults will be relocated from its original location in a healthy condition.

In order to validate the above mentioned assumption, the 2-hp induction motor, whose laboratory test results were presented in Section IV, was simulated using Flux-2D-MAGSOFT TSFE software. The simulation results of the two case studies of a healthy rotor cage and a cage with three broken bars are presented here as validation of this assumption. In Fig. 25, the rotor
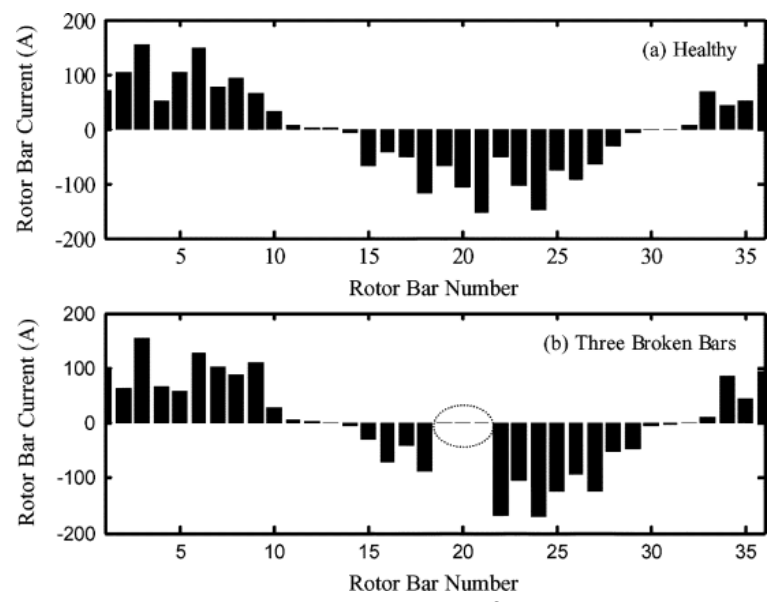

Fig. 27. FE simulation results of the rotor bar current distributions in (a) a healthy cage and (b) a cage with three broken bars fault.
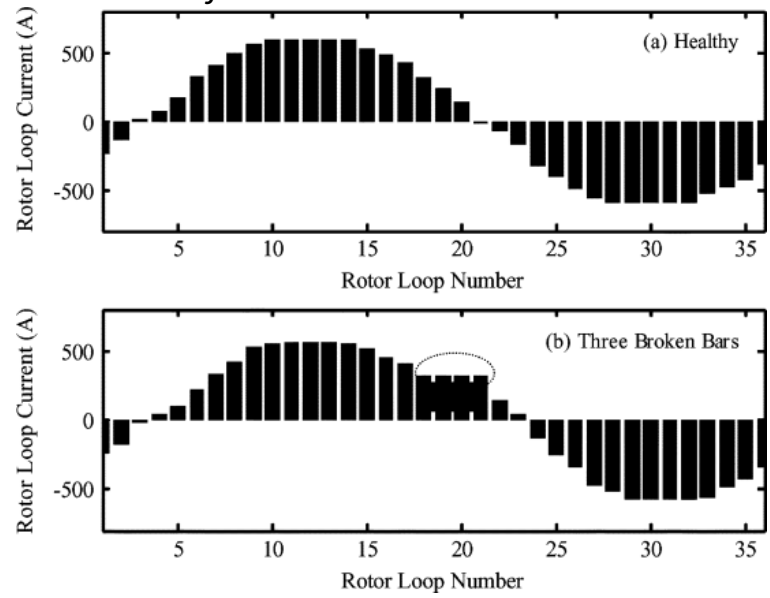

Fig. 28. FE simulation results of the rotor loop current distributions in (a) a healthy cage and (b) a cage with three broken bars fault. 
bar current of the 22nd bar are shown for the healthy case and the case of three bar breakages, where the 19th, 20th, and 21st bars were broken. Meanwhile, in Fig. 26, the healthy loop current of the 22nd loop (located between the 21st and 22nd bars) are shown for the above-mentioned healthy and broken-bar cases. Of course, these figures are not in phase because of the fact that the starting transient period will be longer in the case of a motor with the broken-bars fault. Examination of these waveforms of Fig. 26 reveals no significant change in the loop current magnitudes. This is happening even for the loop immediately adjacent to the bar breakage.

Moreover, in Fig. 27, the bar current distributions of a healthy cage and a cage with three broken bars, located at bar numbers 19, 20, and 21, are shown at an instance in the TSFE simulation (or for a rotor position). Meanwhile, the rotor loop current distributions are shown in Fig. 28, where the loops numbered 18, 19, 20, and 21 in the healthy cage are absent in the cage with three broken bars fault. As one can observe from Fig. 28, the healthy loop currents in a cage with three broken bars did not suffer significant change in comparison with their values in the healthy cage. The most important observation is that the loop current distribution shows that the rotor magnetic field, which is established due to the loop current distributions at any instance, has a displacement in its positive neutral axis due to the three broken bars shown at that specific time sample (rotor position) shown in Fig. 28(b).

The objective of this appendix is to present the mathematical proof of (7) and (8) in Section II. Moreover, it will be shown analytically that an induction motor will fail if the number of adjacent broken bars reaches to half the number of bars per pair of poles.

Here, a similar procedure, as discussed in the Section II for a cage with one broken bar, can be applied for a rotor cage with $n_{b}$ adjacent broken bars. The distortion step on the rotor MMF or the unknown value of the large loop current due to $n_{b}$ broken bars, $i_{X}$, can be expressed in terms of the other healthy loop currents as follows:

$$
i_{X}=\frac{\sum_{k=m}^{m-n_{b}} i_{L k}}{\left(n_{b}+1\right)}
$$

Considering the positive portion of the rotor MMF profile similar to the one shown in Fig. 4 but with $n_{b}$ adjacent broken bars and knowing that the magnetic axis is located where the area of this portion is equally divided (center of mass of the MMF), yields

$$
(\gamma) i_{X}+\left(\frac{2 \pi}{N_{b}}\right) \sum_{k=m-1}^{m-n_{b}} i_{L k}=\left[\left(n_{b}+1\right)\left(\frac{2 \pi}{N_{b}}\right)-\gamma\right] i_{X} .
$$

Now, using $i_{X}$ from (B.1) and solving (B.2) for $\gamma$ yields 


$$
\gamma=\frac{1}{2 i_{X}} \cdot \frac{2 \pi}{N_{b}}\left[\sum_{k=m}^{m-n_{b}} i_{L k}-\sum_{k=m-1}^{m-n_{b}} i_{L k}\right]
$$

which gives

$$
\gamma=\left(\frac{\pi}{N_{b}}\right)\left(\frac{i_{m}}{i_{X}}\right)
$$

Hence, the angular shift of the magnetic axis can be calculated by

$$
\Delta \gamma=\gamma-\frac{\pi}{N_{b}}=\left(\frac{\pi}{N_{b}}\right)\left(\frac{i_{m}-i_{X}}{i_{X}}\right) .
$$

Substituting (B.1) into (B.5) yields

$$
\Delta \gamma=\left(\frac{\pi}{N_{b}}\right)\left(\frac{\left(n_{b}+1\right) i_{m}-\sum_{k=m}^{m-n_{b}} i_{L k}}{\sum_{k=m}^{m-n_{b}} i_{L k}}\right) .
$$

Accordingly, the estimated swing angle of the magnetic axis $\Delta \tilde{\delta}$, in radians, is given below [1]

$$
\Delta \tilde{\delta}=\frac{2 \Delta \gamma}{2}=\left(\frac{\pi}{N_{b}}\right)\left(\frac{n_{b} i_{m}-\sum_{k=m-1}^{m-n_{b}} i_{L k}}{i_{m}+\sum_{k=m-1}^{m-n_{b}} i_{L k}}\right) .
$$

Considering only the fundamental component of loop currents yields

$$
\begin{aligned}
& \Delta \tilde{\delta}=\left(\frac{\pi}{N_{b}}\right) \\
& \times\left(\frac{n_{b} I_{r} \cos \left(\omega_{r} t\right)-\sum_{k=m-1}^{m-n_{b}} I_{r} \cos \left(\omega_{r} t-\frac{2 k \pi}{N_{b}}\right)}{I_{r} \cos \left(\omega_{r} t\right)+\sum_{k=m-1}^{m-n_{b}} I_{r} \cos \left(\omega_{r} t-\frac{2 k \pi}{N_{b}}\right)}\right) .
\end{aligned}
$$


Substituting $t=0$ in (B.8), due to that fact that $k=m$ in case (1) discussed in Section II, yields

$$
\Delta \tilde{\delta}=\left(\frac{\pi}{N_{b}}\right)\left(\frac{\left(n_{b}+1\right)-\sum_{k=0}^{n_{b}} \cos \left(\frac{2 k \pi}{N_{b}}\right)}{\sum_{k=0}^{n_{b}} \cos \left(\frac{2 k \pi}{N_{b}}\right)}\right) .
$$

Using the following trigonometry identities [12]

$$
\sum_{k=0}^{n_{b}} \cos \left(\frac{2 k \pi}{N_{b}}\right)=\frac{1}{2}+\frac{\sin \left[\left(2 n_{b}+1\right)\left(\frac{\pi}{N_{b}}\right)\right]}{2 \sin \left(\frac{\pi}{N_{b}}\right)}
$$

(B.10)

Equation (B.9) can be rewritten as follows

$$
\Delta \tilde{\delta}=\left(\frac{\pi}{N_{b}}\right)\left(\frac{\left(n_{b}+1\right)-\frac{1}{2}-\frac{\sin \left[\left(2 n_{b}+1\right)\left(\frac{\pi}{N_{b}}\right)\right]}{2 \sin \left(\frac{\pi}{N_{b}}\right)}}{\frac{1}{2}+\frac{\sin \left[\left(2 n_{b}+1\right)\left(\frac{\pi}{N_{b}}\right)\right]}{2 \sin \left(\frac{\pi}{N_{b}}\right)}}\right) .
$$

Further simplification yields

$$
\begin{gathered}
\Delta \tilde{\delta}=\left(\frac{\pi}{N_{b}}\right) \\
\times\left(\frac{\left(2 n_{b}+1\right) \sin \left(\frac{\pi}{N_{b}}\right)-\sin \left[\left(2 n_{b}+1\right)\left(\frac{\pi}{N_{b}}\right)\right]}{\sin \left(\frac{\pi}{N_{b}}\right)+\sin \left[\left(2 n_{b}+1\right)\left(\frac{\pi}{N_{b}}\right)\right]}\right) .
\end{gathered}
$$

In order to take into account the harmonics effect, the factor $k_{h}$, elaborated earlier in the paper, is inserted in this formulation as follows: 


$$
\tilde{\Delta}=k_{h}\left(\frac{\pi}{N_{b}}\right)\left(\frac{\left(2 n_{b}+1\right)-\xi}{1+\xi}\right)
$$

where

$$
\xi=\frac{\sin \left[\left(2 n_{b}+1\right)\left(\pi / N_{b}\right)\right]}{\sin \left(\pi / N_{b}\right)} .
$$

It should be noticed that if $\xi=-1$, then $\Delta \delta \rightarrow \infty$. It means that an induction machine with $n_{b}$ adjacent broken bars will fail when $\sin \left[\left(2 n_{b}+1\right)\left(\pi / N_{b}\right)\right]=-\sin \left(\pi / N_{b}\right)$. In other words, the failure happens when $\left(2 n_{b}+1\right)\left(\pi / N_{b}\right)=\left(\pi / N_{b}\right)+\pi$, from which one deduces that the machine will fail when $n_{b}$ reaches a value equal to $\left(N_{b} / 2\right)$.

\section{References}

1. B. Mirafzal and N. A. O. Demerdash, "Induction machine broken-bar fault using the rotor spacevector magnetic field orientation", IEEE Trans. Ind. Appl., vol. 40, no. 2, pp. 534-542, Mar./Apr. 2004.

2. S. Williamson and A. C. Smith, "Steady state analysis of 3-phase cage motors with rotor-bar and end-ring faults", Proc. Inst. Elec. Eng., vol. 129, no. 3, pp. 93-100, 1982.

3. W. Deleroi, "Squirrel cage motor with broken bar in the rotor-physical phenomena and their experimental assessment", Proc. Int. Conf. Electrical Machines, pp. 767-770, 1982.

4. W. Deleroi, "Broken bar in squirrel cage rotor of induction motor part I: Description by superimosed fault currents", Arch. Elektrotech. (Germany), vol. 67, pp. 91-99, 1984.

5. G. B. Kliman, R. Koegle, J. Stein, R. D. Endicott and M. W. Madden, "Noninvasive detection of broken rotor bars in operating induction motors", IEEE Trans. Energy Convers., vol. 3, no. 4, pp. 873-879, Dec. 1988.

6. G. B. Kliman, W. J. Premerlani, B. Yazici, R. A. Koegl and J. G. Mazereeuw, "Sensorless online motor diagnostics", IEEE Comput. Appl. Power, vol. 10, no. 2, pp. 39-43, Apr. 1997.

7. G. B. Kliman, Spectral analysis of induction motor current to detect rotor faults with reduced false alarms, Sep. 1991.

8. P. Vas, Electrical Machines and Drives: A Space-Vector Theory Application, U.K., London:Oxford Univ. Press, 1992.

9. B. Mirafzal, Incepient fault diagnosis in squirrel-cage induction motors, Aug. 2005.

10. A. V. Oppenheim, R. W. Schafer and J. R. Buck, Discrete-Time Signal Processing, NJ, Upper Saddle River:Prentice-Hall, 1999.

11. M. E. H. Benbouzid and G. B. Kliman, "What stator current processing-based technique to use for induction motor rotor faults diagnosis?", IEEE Trans. Energy Convers., vol. 18, no. 2, pp. 238244, Jun. 2003.

12. C. R. Wylie and L. C. Barrett, Advanced Engineering Mathematics, New York:McGraw-Hill, 1982. 
